\title{
Diabetic choroidopathy: a review of the current literature
}

\author{
Diana Melancia ${ }^{1,2}$ - André Vicente ${ }^{3,4}$ • João Paulo Cunha ${ }^{3,5}$ - Luís Abegão Pinto ${ }^{6,7}$. \\ Joana Ferreira ${ }^{3,5}$
}

Received: 9 February 2016/Revised: 12 April 2016/Accepted: 14 April 2016/Published online: 25 April 2016

(C) Springer-Verlag Berlin Heidelberg 2016

\begin{abstract}
Diabetic retinopathy is an increasingly prevalent disease, and a leading contributor to the burden of all-cause blindness worldwide. In addition to retinal changes, choroidal abnormalities are common in patients with diabetes. The first studies concerning this vascular structure were based on histologic, indocyanine angiography and laser Doppler flowmetry techniques, but the development of new optical coherence tomography (OCT) technologies and imaging software for enhanced depth imaging (EDI)-OCT in recent years has made it possible to provide more detailed images of the choroidal anatomy and topography.

In diabetic patients, several choroidal changes have been described in the literature throughout the years; the recent focus is choroidal thickness, which is significantly different from that in healthy patients. However, understanding choroidal manifestations of diabetic eye disease remains a real challenge, and this gap is hindering efforts towards better defining
\end{abstract}

Joana Ferreira

joanaptf@gmail.com

1 Neurology Department, Central Lisbon Hospital Center, Lisbon, Portugal

2 Institute of Pharmacology and Neurosciences, Faculty of Medicine of Lisbon University, Lisbon, Portugal

3 Ophthalmology Department, Central Lisbon Hospital Center, Lisbon, Portugal

4 Faculty of Medicine of Lisbon University, Lisbon, Portugal

5 Faculty of Medical Sciences of New University, Lisbon, Portugal

6 Ophthalmology Department, Northern Lisbon Hospital Center, Lisbon, Portugal

7 Visual Sciences Study Center, Faculty of Medicine, Lisbon University, Lisbon, Portugal choroidal evaluation as a predictive factor for disease evolution and treatment response.

This review aims to summarize the recent literature concerning changes in choroidal structure in diabetic patients, the relationship to diabetic retinal disease progression, and finally, the current and potential application of the measurement of variations in choroidal thickness for patient management.

Keywords Diabetic choroidopathy · Diabetic retinopathy · Enhanced depth imaging · Optical coherence tomography

\section{Diabetic choroidopathy}

Diabetic retinopathy (DR) is a leading cause of visual impairment and blindness, affecting almost $35 \%$ of all diabetic patients worldwide [1]. The main retinal insults are vascular and neural, with vessel occlusion and leakage, leukostasis, and alteration of the blood-retinal barrier as a result of dysfunctional tight junctions, causing increased vascular permeability, generation of free radicals, mitochondrial dysfunction, and neuronal swelling and apoptosis [2]. The visual impairment is attributed primarily to retinal damage, but evidence from histologic, angiographic and laser Doppler flowmetry studies suggests the simultaneous presence of diabetic choroidopathy (DC). The choroid is an important vascular tissue, responsible for the blood supply to the outer layers of the retina, including the retinal pigmented epithelium (RPE) and photoreceptors, and is the only source of metabolic exchange for the avascular fovea [3]. The choroidal abnormalities in diabetic eyes include microaneurysms, dilatation and obstruction of the choriocapillaris, vascular remodelling with increased vascular tortuosity, vascular dropout, areas of vascular non-perfusion and choroidal neovascularization. 
Until recently, evaluation of the choroid was typically performed using indocyanine green angiography (ICGA) or laser Doppler flowmetry. These techniques, however, are only able to show vascular abnormalities and are not able to provide any information concerning anatomic and structural features of the choroid.

With the recent development of spectral domain optical coherence tomography (SD-OCT) and enhanced depth imaging (EDI)-OCT software, a more detailed evaluation of the choroid became possible. The classical OCT devices were unhelpful, as the RPE blocked the signal from the choroid. By moving the peak of the sensitivity curve to the sclera, maximizing sensitivity and detail, SD-OCTand EDI-OCT software in particular-provide a better view of the choroidal cross-sectional structure, thickness and choroidal-scleral interface [4]. This technique launched a new era in choroidal evaluation and encouraged further research on possible clinical applications for choroidal thickness (CT) measurement. Nowadays, the role of $\mathrm{CT}$ as a predictive factor of diabetic eye disease is almost nonexistent. Nevertheless, a recent study reported that CT may be useful for predicting short-term outcomes of antivascular endothelial growth factor (VEGF) treatment in patients with diabetic macular edema (DME), as greater baseline CT was significantly associated with better visual and anatomic outcomes after intravitreal anti-VEGF injections [5]. Research is ongoing in efforts to better understand and to identify other possible roles for choroidal changes that are seen, albeit inconsistently, in diabetic patients.

The aim of this review is to summarize recent literature regarding the use of the newer OCT technology for evaluation of the choroid in diabetic patients, particularly CT and its relation to the severity of DR.

\section{Imaging the choroid}

Histologic studies of diabetic patients have revealed many changes consistent with vascular anomalies: atrophy and loss of the choriocapillaris endothelium, capillary narrowing and dropout, laminar deposits, tortuous and beaded vessels, and choroidal neovascularization [6, 7]. In more advanced cases, even larger vessels have shown onion-skin changes and aneurysmal formation [8]. They were also found to be present in diabetic patients without clinical DR, possibly clarifying the unexplained loss of visual acuity in diabetic eyes without clinical evidence of DR $[6,9]$.

Studies using fluorescein angiography and ICGA have shown several filling abnormalities in diabetic eyes. Reports of patients with mild non-proliferative diabetic retinopathy (mNPDR) have described a characteristic "salt-and-pepper" pattern caused by selective filling of the choriocapillaris, in contrast to the normal ground-glass appearance [10]. Several other abnormalities have been observed later in the disease course, notably hypofluorescent spots and both small and large hyperfluorescent spots. These abnormal patterns are well correlated with the severity of DR, HbA1c levels and poor diabetes control [11-13].

An increased resistance index is seen when laser Doppler flowmetry is used to access choroidal blood flow beneath the fovea, possibly resulting from the progressive reduction of choroidal blood flow and volume in patients with diabetes, even in eyes with clinically undetected DR $[14,15]$. This suggests that choroidopathy might trigger the development of retinopathy due to retinal tissue hypoxia and overexpression of VEGF, contributing to further retinal damage and macular edema. Reduced blood flow in the central ophthalmic artery and vein was also found in diabetic patients, with a steeper decrease in patients with proliferative diabetic retinopathy (PDR) [16]. Inconsistencies remain among published studies with regard to choroidal blood flow measurements in diabetic patients, as CT has been reported to be reduced (as stated above), unchanged (particularly in the early stages of diabetic disease) and even increased (mNPDR or untreated PDR) [17].

Recent developments in SD-OCT and EDI-OCT software have allowed CT to be studied in many conditions. Studies in normal eyes have revealed variations in CT with age (decrease of $15.6 \mu \mathrm{m}$ with each decade of life), axial length $(\mathrm{AL} ;-17$ to $-58.2 \mu \mathrm{m}$ per millimeter of $\mathrm{AL})$ [18], and even time of day, with diurnal variation in CT that can be as great as $67 \mu \mathrm{m}[3,19,20]$. In addition, the thickness of the central choroid seems to increase with progressive nasal and temporal thinning, a pattern that is characteristic of all diabetic patients regardless of DR grade $[3,21,22]$. Another OCT technology, sweptsource (SS)-OCT, uses a different light source and detection method, and offers the advantages of higher imaging speed and accuracy, which are important in analyzing the choroid [23-27]. Lastly, the recent development of OCT angiography enables non-invasive visualization of vascular structures based on the motion of erythrocytes within the retinal and choroidal vasculature. Given the importance of documenting choriocapillaris and choroidal vasculature in vivo, this technique will have a role in the investigation of the choroid in both physiological and pathological conditions [28, 29].

The advent of these technologies has facilitated a large number of studies focused on the structure of the choroid in diabetic patients, and recent results show a relevant association between DR and CT. 


\section{Diabetic choroidopathy: optical coherence tomography}

\section{Decreased choroidal thickness}

Many authors have found that decreased CT is associated with diabetes [21, 22, 30-33], and some have suggested that this might well relate to the instigated retinal insult-since the choroid is the major source of oxygen and nutrition to the outer layers of the retina and RPE, disturbances in this structure may lead to increased susceptibility to retinal tissue hypoxia and ischemia seen in diabetes mellitus. Comparisons of CT among diabetic patients with mNPDR, DME and PDR has revealed a trend towards significant choroidal thinning in eyes with DR (Table 1).

Querques et al. [34] and Esmaeelpour et al. [30] reported a significant decrease in CT among diabetic patients without clinical evidence of retinopathy, suggesting that decreased choroidal blood flow may be the primary event. These results are consistent with the findings of vascular studies of the choroid $[15,35]$. Esmaeelpour, who used thickness maps of $36^{\circ} \times 36^{\circ}$ instead of single-point measurements, reported choroidal thinning in an NDR group, particularly in the subfoveal $(p=0.001)$ and inferior regions $(p=0.05)$. Furthermore, the authors extended the thickness maps to the retina and reported perimacular thinning, possibly caused by atrophy of the nerve fiber layer, not visible with slit lamp examination. However, in the presence of macular lesions (M1 and M2), there was no apparent choroidal thinning directly below the lesions [30].

\section{Increased choroidal thickness}

Some data, however, disagree with the findings above, suggesting that rather than thinning, the choroid may become thicker in eyes with DR $[32,33,36]$. Kim et al., for example, found significant choroidal thickening in eyes with DR, increasing as the disease progressed in severity from severe NPDR (sNPDR; $p<0.05)$ to untreated PDR $(p<0.01)$ [36]. These inconsistencies were justified by the authors as possible differences in patient profiles and study limitations (see below; Table 1). The study by Kase et al. somewhat agrees with these findings, as their results show a non-significant trend towards increased choroidal layer thickness with increasing DR severity [37]. However, DR patients in that study were subdivided into an under-treatment group receiving antidiabetic drugs and a no-treatment group, and only the notreatment group showed a significant change in CT, decreasing in the mNPDR stage $(p<0.05)$ and increasing posteriorly in the sNPDR and PDR groups $(p<0.05)$. Furthermore, DME patients were not considered separately. These results suggest that a chronic hyperglycemia may be a factor in further deterioration of damaged choroidal microvasculature.
It is still unclear whether the choroidal changes are primary or independent of the retinopathy. Some authors contend that primary choroidal angiopathy is present before the onset of DR, while others believe these to be unrelated events $[32,33,36]$, with choroidopathy occurring only in more severe grades of DR $[21,22,24]$ or worsening with increasing DR severity [36, 37].

A recent study by Ferreira et al., which evaluated CT among diabetic patients without DR, showed a significant increase in CT at $1500 \mu \mathrm{m}$ superior to the fovea $(p=0.021)$. None of the other 12 location comparisons were statically significant ( $p>0.05$; Fig. 1) [38]. These changes in CT may well represent early pre-clinical changes in diabetic patients, but the reason for the inconsistencies in the location and direction of $\mathrm{CT}$ changes remains unknown.

Ferrara et al., who included 76 eyes in their recent study using SS-OCT (22 eyes of 22 patients with DM but without DR, 20 eyes of patients with NPDR, 15 eyes with PDR, and 26 eyes of healthy age-matched controls), detected vascular remodelling in all DM patients corresponding to irregular, tortuous and beaded choroidal vessels with focal dilation and narrowing. Small vessel loss in the topography of previous retinal photocoagulation was another relevant observation by the authors [39].

\section{Choroidal thickness and diabetic macular edema}

Uncertainties also exist concerning the connection between the evolution of $\mathrm{CT}$ and increasing severity of diabetic retinopathy. Some studies have found a correlation with increasing DR severity [22], while others have found no correlation between CT and grade of DR [21, 32, 40]. Thus the exact relationship between $\mathrm{CT}$ and the severity of DR remains largely unknown, and although some authors have cautiously suggested choroidal thinning in areas with documented retinal thickening (Querques et al. 2012; data not shown) [34], no significant correlation between retinal and $\mathrm{CT}$ has been found $[21,24,33]$. The exception is patients with macular edema (with a thicker retina), who have clinically significant subfoveal choroidal thinning compared to healthy eyes, but have a tendency towards a thicker choroid when compared to other grades of the disease, NPDR and PDR. While very few authors have compared subgroups of diabetic patients given the small samples in each group, Kim et al. reported significant choroidal thickening in DME patients versus non-DME patients $(p<0.05)$. Furthermore, among DME patients, CT appeared to be greater in the serous retinal detachment-type (SRD-type) group than patients with cystoid-type macular edema $(p<0.05)$. These results are in agreement with other observations of a tendency towards a thicker choroid in patients with DME, although the difference was not significant $[21,22,30-32]$. Some authors, however, have cautiously reported a thinner choroid in the presence of clinically significant macular edema (CSME) [34, 35, 41], explaining this pattern as an artefact induced by macular 
Table 1 Clinical studies comparing subfoveal choroidal thickness in eyes with different grades of diabetic disease

\begin{tabular}{|c|c|c|c|c|c|}
\hline Study & $\begin{array}{l}\text { Number } \\
\text { of } \\
\text { patients }\end{array}$ & Method & Groups & $\mathrm{SCT}$ & $p$ value \\
\hline \multirow{5}{*}{$\begin{array}{r}\text { Esmaeelpour } \\
\text { [30], } 2011\end{array}$} & \multirow[t]{5}{*}{42} & \multirow{5}{*}{$\begin{array}{r}\text { High-speed } \\
\text { 3D-OCT }\end{array}$} & Control & $327 \pm 74$ & $p<0.001$ \\
\hline & & & NDR & $214 \pm 55$ & $p<0.001$ \\
\hline & & & M1 & $208 \pm 49$ & $p<0.001$ \\
\hline & & & M2 & $205 \pm 54$ & $p<0.001$ \\
\hline & & & CSME & $211 \pm 76$ & \\
\hline \multirow{3}{*}{$\begin{array}{r}\text { Esmaeelpour } \\
\text { [31], } 2012\end{array}$} & \multirow[t]{3}{*}{33} & \multirow{3}{*}{$\begin{array}{l}\text { High-speed } \\
\text { 3D-OCT }\end{array}$} & Control & $388 \pm 109$ & $p<0.001$ \\
\hline & & & NDR & $291 \pm 64$ & $p<0.001$ \\
\hline & & & DR & $303 \pm 82$ & \\
\hline \multirow{4}{*}{$\begin{array}{l}\text { Querques } \\
\text { [34], } 2012\end{array}$} & \multirow[t]{4}{*}{63} & \multirow[t]{4}{*}{ EDI-OCT } & Control & $309.8 \pm 58.5$ & $p<0.001$ \\
\hline & & & NDR & $238.4 \pm 47.9$ & $p<0.001$ \\
\hline & & & NPDR & $207.0 \pm 55.9$ & $p<0.001$ \\
\hline & & & $\begin{array}{c}\text { NPDR/ } \\
\text { CS- } \\
\text { ME }\end{array}$ & $190.8 \pm 58.5$ & \\
\hline \multirow{4}{*}{$\begin{array}{l}\text { Regatieri } \\
\text { [21], } 2012\end{array}$} & \multirow[t]{4}{*}{49} & \multirow[t]{4}{*}{ HD-OCT } & Control & $232.3 \pm 15.2$ & NS \\
\hline & & & mNPDR & $222.0 \pm 21.6$ & $p<0.001$ \\
\hline & & & PDR & $162.7 \pm 7.0$ & $p<0.001$ \\
\hline & & & $\begin{array}{c}\text { NPDR/ } \\
\text { DME }\end{array}$ & $169.5 \pm 14.7$ & \\
\hline
\end{tabular}

\begin{tabular}{ccclll} 
Vujosevic & 102 & SD-OCT & Control & $329.5 \pm 65.2$ & NS \\
[33], 2012 & & & NDR & $280.6 \pm 65.2$ & $p<0.05$ \\
& & NPDR & $279.4 \pm 81.6$ & $p<0.05$ \\
& & PDR & $230.5 \pm 25.8$ & \\
Kim [36], & \multirow{2}{*}{235} & EDI-OCT & Control & $276.0 \pm 58.1$ & - \\
2013 & & & NDR & $262.3 \pm 68.4$ & $p<0.01^{*}$ \\
& & mNPDR & $244.6 \pm 77.0$ & $p<0.01^{*}$ \\
& & SNPDR & $291.1 \pm 107.7$ & $p<0.05^{*}$ \\
& & PDR & $363.6 \pm 74.9$ & -
\end{tabular}

No relationship between macular lesions and choroidal thinning

Previous treatments (PRP or anti-VEGF) were not mentioned.

PRP and anti-VEGF-treated patients were excluded.

All DME patients had received PRP more than 6 months earlier; untreated PDR patients were not included.

Cirrus HD-OCT was less accurate in identifying small and focal lesions on the choriocapillaris.

Patients previously treated with PRP or anti-VEGF drugs were excluded.

Data on DME patients was not shown.

Patients with previous PRP treatments were considered separately, and eyes previously treated with antiVEGF were excluded.

Patients with and without DME were compared, disregarding the grade of DR, and groups with milder retinopathy (NDR, mild NPDR) typically had patients without DME, as opposed to patients with more severe DR that had a greater number of DME patients.

DME patients revealed no significant differences in CT compared to PDR and sNPDR patients without DME, but a slight trend towards a thicker choroid.

There was no reference to whether PDR patients received PRP or anti-VEGF treatment. 
Table 1 (continued)

\begin{tabular}{|c|c|c|c|c|c|c|}
\hline Study & $\begin{array}{l}\text { Number } \\
\text { of } \\
\text { patients }\end{array}$ & Method & Groups & SCT & $p$ value & Valuable points/limitations \\
\hline $\begin{array}{c}\mathrm{Xu}[40] \\
2013\end{array}$ & 246 & SD-OCT & $\begin{array}{l}\text { Control } \\
\text { DM } \\
\text { NDR } \\
\text { DR }\end{array}$ & $\begin{array}{l}250 \pm 103 \\
266 \pm 108 \\
251 \pm 104 \\
249 \pm 86\end{array}$ & $P=0.02$ & $\begin{array}{l}\text { Comparisons to diabetic } \\
\text { patients ignored the presence } \\
\text { or absence of DR and its } \\
\text { grade. } \\
\text { There were few patients with } \\
\text { DR (23) among the } 246 \\
\text { diabetic patients. }\end{array}$ \\
\hline $\begin{array}{l}\text { Adhi [24], } \\
2013\end{array}$ & 33 & SD-OCT & $\begin{array}{l}\text { Control } \\
\text { NPDR } \\
\text { PDR } \\
\text { DME }\end{array}$ & $\begin{array}{l}276.4 \\
252.9 \\
209.6 \\
211.6\end{array}$ & $\begin{array}{l}\mathrm{NS}^{* *} \\
p<0.05 \\
p<0.05\end{array}$ & $\begin{array}{l}\text { Anti-VEGF-treated DME } \\
\text { patients }(57 \%) \text { were not } \\
\text { studied separately. } \\
\text { All eyes with PDR and DME } \\
\text { had received PRP, and time } \\
\text { between PRP and CT } \\
\text { measurement was ignored. } \\
\text { Blood pressure and HbA1c } \\
\text { values were ignored; groups } \\
\text { were not matched for axial } \\
\text { length. } \\
\text { Subgroups of DR were small. }\end{array}$ \\
\hline $\begin{array}{l}\text { Ünsal [22], } \\
2014\end{array}$ & 151 & EDI-OCT & $\begin{array}{l}\text { Control } \\
\text { mNPDR } \\
\text { PDR } \\
\text { NPDR/ } \\
\text { DME }\end{array}$ & $\begin{array}{l}259.1 \pm 13.1 \\
235.4 \pm 84.5 \\
203.8 \pm 47.6 \\
206.8 \pm 45.4\end{array}$ & $\begin{array}{l}\text { NS } \\
p<0.01 \\
p<0.01\end{array}$ & $\begin{array}{l}\text { All PDR patients had already } \\
\text { received PRP treatment, and } \\
\text { time between PRP and CT } \\
\text { measurement was not } \\
\text { considered. } \\
\text { Axial length, which affects CT } \\
\text { values, was not evaluated. }\end{array}$ \\
\hline $\begin{array}{l}\text { Kase [37], } \\
2015\end{array}$ & 86 & SD-OCT & $\begin{array}{l}\text { Control } \\
\text { NDR } \\
\text { mNPDR } \\
\text { sNPDR } \\
\text { PDR } \\
\text { DME }\end{array}$ & $\begin{array}{l}272 \pm 72 \\
255 \pm 68 \\
253 \pm 81 \\
309 \pm 80 \\
287 \pm 71 \\
276 \pm 71\end{array}$ & $\begin{array}{l}\text { NS } \\
\text { NS } \\
\text { NS } \\
\text { NS } \\
\text { NS }\end{array}$ & $\begin{array}{l}\text { None of the diabetic patients } \\
\text { received any PRP or anti- } \\
\text { VEGF treatment. } \\
\text { Subdivided DR patients into } \\
\text { groups receiving oral anti- } \\
\text { diabetic drugs and those } \\
\text { without therapy; only } \\
\text { patients in the no-treatment } \\
\text { group experienced } \\
\text { significant differences in CT } \\
\text { with increasing severity of } \\
\text { DR. } \\
\text { DME patients were not } \\
\text { considered separately. }\end{array}$ \\
\hline $\begin{array}{l}\text { Ferreira [38], } \\
\quad 2015\end{array}$ & 125 & EDI-OCT & $\begin{array}{l}\text { Control } \\
\text { NDR }\end{array}$ & $\begin{array}{l}240.6 \pm 7.92 \\
267.9 \pm 6.16\end{array}$ & $p<0.05$ & $\begin{array}{l}125 \text { diabetic patients without } \\
\text { DR, } \\
\text { CT thicker at } 1500 \mu \mathrm{m} \text { superior } \\
\text { to the fovea }\end{array}$ \\
\hline
\end{tabular}

$S C T$ subfoveal choroidal thickness, $N S$ not significant, $N A$ not available, $N D R$ no diabetic retinopathy, $M 1$ microaneurysms within 1 disc-diameter of the fovea, $M 2$ exudates within 1 disc-diameter of the fovea, CSME clinically significant macular edema, $D M$ diabetes mellitus, $D M E$ diabetic macular edema, NPDR non-proliferative diabetic retinopathy, $m N P D R$ mild to moderate NPDR, $s N P D R$ severe NPDR, $P D R$ proliferative diabetic retinopathy, $P R P$ pan-retinal laser photocoagulation

* Compared with the PDR group

** Significant in other peripheral regions (see text)

edema, inhibiting the signal transduction and reflection from the choroid due to increased ocular opacity. In contrast, a study by Gerendas et al. reported that this CT thinning was consistent among 142 eyes with DME, and that 
Fig. 1 Measurements of choroidal thickness at 13 locations - subfoveal area (a) and at $500-\mu \mathrm{m}$ intervals from the fovea to $1500 \mu \mathrm{m}$ nasal (a), $1500 \mu \mathrm{m}$ temporal (a), $1500 \mu \mathrm{m}$ superior (b) and $1500 \mu \mathrm{m}$ inferior (c) - in diabetic patients without DR
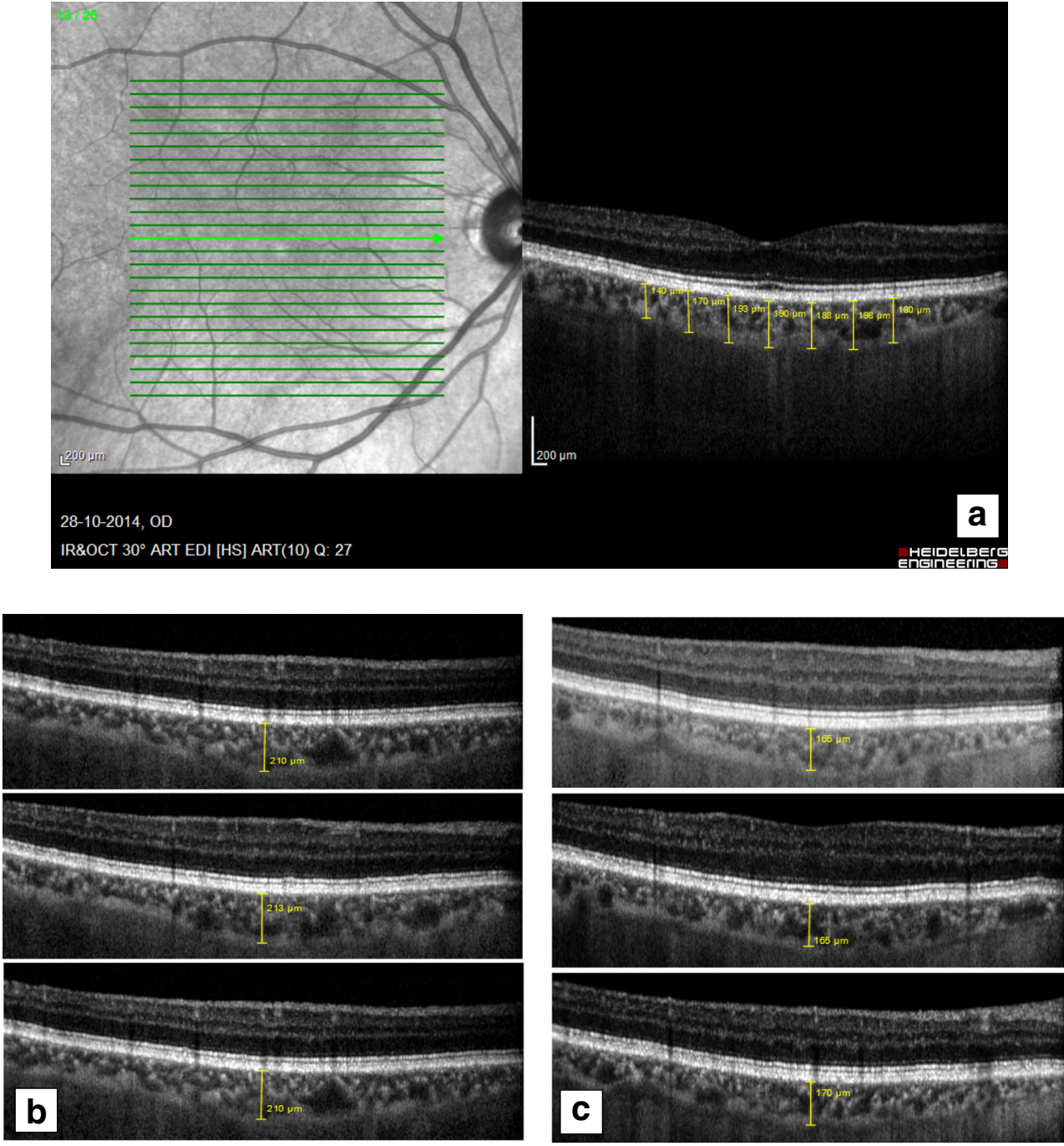

fellow eyes without macular edema were equally affected, suggesting a systemic pathophysiologic mechanism [41].

\section{Choroidal thickness after treatment for diabetic retinopathy}

The results discussed above should be interpreted with caution, however, as most patients included in PDR groups were not treatment-naïve, and had already undergone pan-retinal laser photocoagulation (PRP) or anti-VEGF treatment. In addition, the time between treatment and measurement of CT was seldom mentioned. There is evidence that PRP may induce long-term thinning of the choroid (possibly by downregulation of VEGF [36]), but in the short term (1 week), it may be responsible for choroidal swelling, probably due to a shifting of blood vessels from the peripheral retina to the foveal area $[42,43]$. Zhu et al. found significant thickening of the subfoveal choroid 1 and 3 months after PRP, versus a significant decrease in $\mathrm{CT}$ in the area subjected to photocoagulation. In the latter, although scar formation may limit a local inflammatory reaction, choroidal inflammation could induce vasodilation of untreated areas, leading to an early increase in CT [42]. Moreover, the effect of anti-VEGF drugs on CT is still not well understood, although some studies have reported choroidal thinning, at least in the first 6 months [44, 45]. Lee et al. investigated changes in CT after intravitreal bevacizumab injection, PRP or both for the treatment of DR, and reported a decrease in CT after all treatments, suggesting that both methods reduced choroidal vascular permeability [46].

Other common limitations were a lack of consideration for local variables influencing CT - particularly age, time of day, and axial length/refractive error - as well as systemic conditions that appear to alter the choroidal structure (see the "Other factors" section below). Some studies suggested the influence of other variables on the visibility of the choroidalscleral interface (CSI) in OCT images and, consequently, CT measurements. Notably, the study by Gupta et al. suggested that a well-defined CSI was present in only $60 \%$ of subjects. The variables believed to be responsible for this CSI measurement 
inaccuracy include axial length, age, diabetes, retinal thickness and ocular opacities [47], which may thus help to explain differences in results and findings among the clinical studies cited in this review.

\section{Others factors influencing choroidal thickness}

In addition to local ocular factors, systemic conditions can influence CT. Control of blood hemoglobin A1c (HbAlc) appears to be directly correlated with $\mathrm{CT}$, as patients with lower baseline HbAlc have shown a significant increase in CT after strict blood sugar control; however, no correlation was found between these choroidal changes and fasting or average blood glucose [48].

In contrast, a significant correlation was found between CT changes and systemic blood pressure control (systolic, diastolic and mean arterial blood pressure) after 2 weeks of hospitalization [49].

Hypertension is a known factor affecting the choroid [49-51], and a recent study by Akay et al. found a significant decrease in CT among patients with high blood pressure $(p<0.001)$, from $1000 \mu \mathrm{m}$ nasally to $1500 \mu \mathrm{m}$ temporally, although there was no significant correlation between blood pressure levels and duration of disease [51].

Hypercholesterolemia, on the other hand, was recently found to cause a focal increase in CT, as reported by Wong et al. The study showed increased CT in the subfoveal 1000- $\mu \mathrm{m}$ nasal and 1000- $\mu \mathrm{m}$ superior areas, and is well supported by animal models demonstrating atherosclerotic changes in the choroid in the presence of high levels of serum cholesterol [52]. Low triglyceride levels also appear to be related to a thicker choroid, but the mechanism remains unknown [53].

All of these systemic imbalances are prone to atherosclerotic changes, and frequently coexist in diabetic patients; thus they warrant further consideration in future studies. However, the complexity of their interactions makes it difficult to contemplate them as isolated variables, and so additional basic studies in experimental models are needed.

\section{Conclusion}

Although it is clear that choroidal changes are present in patients with in diabetes, it remains unclear whether these changes are predictive, modulatory, causative or independent factors for DR, and the results from clinical studies remain inconsistent.

The majority of clinical findings supported by histology, laser Doppler flowmetry and indocyanine green angiography suggest choroidal thinning after the onset of diabetes in the absence of clinical evidence of DR, which may account for the visual defects reported by these patients. However, slightly contradictory results, suggesting early thinning with later thickening, or completely opposite results showing choroidal thickening or the appearance of CT abnormalities in secondary stages of DR, have also been obtained.

Differences in methods of choroidal evaluation may account for these conflicting results, as vascular abnormalities are most commonly found in media-peripheral regions, and OCT exams tend to focus on the central macular/foveal region. In addition, CT appears to be influenced by many factors other than the severity of DR. A prior anti-VEGF or laser (PRP) treatment was recently shown to have modulatory effects on choroidal vessels; hence, the CT and time between treatment and measurement should not be disregarded when designing clinical studies. The presence of DME may also interfere with the measurement of CT, or may even influence choriocapillaris function, as well as other local and systemic factors.

Lastly, although the pattern of diabetic choroidopathyrelated changes in $\mathrm{CT}$ is still not well understood, it may have a predictive role for diabetic eye disease in the future. Studies in age-related macular degeneration (AMD) have shown that CT correlates with best-corrected visual acuity (BCVA), and is helpful for predicting non-exudative disease and progression of geographic atrophy as well as treatment response and visual outcome in exudative AMD [54, 55]. Rayess et al. similarly described a possible role for CT as a predictor of visual and treatment outcome in patients with DME, as patients with thicker CT had anatomic and functional responses [5].

In conclusion, with the advent of the latest OCT technologies, diabetic choroidopathy has become a highly studied clinical entity garnering great interest among researchers. Nonetheless, the relationship between DC and DR, and even the role of DC in diabetic eye disease, remains unknown, and further investigation is warranted.

\section{Compliance with ethical standards}

Funding No funding was received for this research.

Conflict of interest All authors certify that they have no affiliations with or involvement in any organization or entity with any financial interest or non-financial interest in the subject matter or materials discussed in this manuscript.

\section{References}

1. Yau JY, Rogers SL, Kawasaki R, Lamoureux EL, Kowalski JW, Bek T et al (2012) Global prevalence and major risk factors of diabetic retinopathy. Diabetes Care 35(3):556-564

2. Antonetti DA, Klein R, Gardner TW (2012) Diabetic retinopathy. N Engl J Med 366(13):1227-1239

3. Mrejen S, Spaide RF (2013) Optical coherence tomography: imaging of the choroid and beyond. Surv Ophthalmol 58(5):387-429 
4. Spaide RF, Koizumi H, Pozzoni MC, Pozonni MC (2008) Enhanced depth imaging spectral-domain optical coherence tomography. Am J Ophthalmol 146(4):496-500

5. Rayess N, Rahimy E, Ying G-S, Bagheri N, Ho AC, Regillo CD, et al. (2015) Baseline choroidal thickness as a predictor for response to anti-vascular endothelial growth factor therapy in diabetic macular edema. Am J Ophthalmol 159(1):85-91.e1-3

6. McLeod DS, Lutty GA (1994) High-resolution histologic analysis of the human choroidal vasculature. Invest Ophthalmol Vis Sci 35(11):3799-3811

7. Lutty GA (2013) Effects of diabetes on the eye. Investig Ophthalmol Vis Sci 54(14):81-87

8. Hidayat AA, Fine BS (1985) Diabetic choroidopathy. Light and electron microscopic observations of seven cases. Ophthalmology 92(4):512-522

9. Cao J, McLeod S, Merges CA, Lutty GA (1998) Choriocapillaris degeneration and related pathologic changes in human diabetic eyes. Arch Ophthalmol 116(5):589-597

10. Weinberger D, Kramer M, Priel E, Gaton DD, Axer-Siegel R, Yassur Y (1998) Indocyanine green angiographic findings in nonproliferative diabetic retinopathy. Am J Ophthalmol 126(2): 238-247

11. Shiragami C, Shiraga F, Matsuo T, Tsuchida Y, Ohtsuki H (2002) Risk factors for diabetic choroidopathy in patients with diabetic retinopathy. Graefes Arch Clin Exp Ophthalmol 240(6):436-442

12. Saracco JB, Gastaud P, Ridings B, Ubaud CA (1982) La Choroïdopathie Diabétique. J Fr Ophtalmol 5(4):231-236

13. Hua R, Liu L, Wang X, Chen L (2013) Imaging evidence of diabetic choroidopathy in vivo: angiographic pathoanatomy and choroidal-enhanced depth imaging. PLoS One 8(12):1-5

14. Schocket LS, Brucker AJ, Niknam RM, Grunwald JE, DuPont J, Brucker AJ (2004) Foveolar choroidal hemodynamics in proliferative diabetic retinopathy. Int Ophthalmol 25(2):89-94

15. Nagaoka T, Kitaya N, Sugawara R, Yokota H, Mori F, Hikichi T et al (2004) Alteration of choroidal circulation in the foveal region in patients with type 2 diabetes. Br J Ophthalmol 88(8):1060-1063

16. Dimitrova G, Kato S, Tamaki Y, Yamashita H, Nagahara M, Sakurai M et al (2001) Choroidal circulation in diabetic patients. Eye (Lond) 15(Pt 5):602-607

17. Savage HI, Hendrix JW, Peterson DC, Young H, Wilkinson CP (2004) Differences in pulsatile ocular blood flow among three classifications of diabetic retinopathy. Investig Ophthalmol Vis Sci 45: 4504-4509

18. Tan CS, Cheong KX (2014) Macular choroidal thicknesses in healthy adults-relationship with ocular and demographic factors. Invest Ophthalmol Vis Sci 55(10):6452-6458

19. Tan CS, Ouyang Y, Ruiz H, Sadda SR (2012) Diurnal variation of choroidal thickness in normal, healthy subjects measured by spectral domain optical coherence tomography. Invest Ophthalmol Vis Sci 53(1):261-266

20. Han Y-S, Lim H-B, Lee S-H, Kim J-Y (2015) Diurnal variation in choroidal and retinal thickness of the early treatment of diabetic retinopathy study macular subfields determined using swept-source optical coherence tomography. Ophthalmologica 233:192-197

21. Regatieri CV, Branchini L, Carmody J, Fujimoto JG, Duker JS (2012) Choroidal thickness in patients with diabetic retinopathy analyzed by spectral-domain optical coherence tomography. Retina 32(3):563-568

22. Ünsal E, Eltutar K, Zirtiloğlu S, Dinçer N, Ozdoğan Erkul S, Güngel H (2014) Choroidal thickness in patients with diabetic retinopathy. Clin Ophthalmol 8:637-642

23. Adhi M, Alwassia AA, Duker JS (2013) Analysis of choroidal thickness in eyes treated with focal laser photocoagulation using SD-OCT. Can J Ophthalmol 48:535e538

24. Adhi M, Brewer E, Waheed NK, Duker JS (2013) Analysis of morphological features and vascular layers of choroid in diabetic retinopathy using spectral-domain optical coherence tomography JAMA Ophthalmol 131:1267e1274

25. Adhi M, Liu JJ, Qavi AH, Grulkowski I, Fujimoto JG, Duker JS (2013c) Enhanced visualization of the choroido-scleral interface using swept-source OCT. Ophthalmic Surg Lasers Imaging Retina 44: S40eS42

26. Adhi M, Liu JJ, Qavi AH, Grulkowski I, Lu CD, Mohler KJ, Ferrara D, Kraus MF, Baumal CR, Witkin AJ, Waheed NK, Hornegger J, Fujimoto JG, Duker JS (2014) Choroidal analysis in healthy eyes using swept-spirce optical coherence tomography compared to spectral domain optical coherence tomography. Am J Ophthalmol 157:1272e1281

27. Ferrara D, Mohler KJ, Waheed N, Adhi M, Liu JJ, Grulkowski I, Kraus MF, Baumal C, Hornegger J, Fujimoto JG, Duker JS (2014) En face enhanced depth swept-source optical coherence tomography features of chronic central serous chorioretinopathy. Ophthalmology 121:719e726

28. Choi W, Mohler KJ, Potsaid B, Lu CD, Liu JJ, Jayaraman V, Cable AE, Duker JS, Huber R, Fujimoto JG (2013) Choriocapillaris and choroidal microvasculature imaging with ultrahigh speed OCT angiography. PLoS One 8, e81499

29. Keane PA, de Salvo G, Sim DA, Goverdhan S, Agrawal R, Tufail A (2015) Strategies for improving detection and diagnosis of neovascular age-related macular degeneration. Clin Ophthalmol 9: $353 \mathrm{e} 366$

30. Esmaeelpour M, Považay B, Hermann B, Hofer B, Kajic V, Hale SL et al (2011) Mapping choroidal and retinal thickness variation in type 2 diabetes using three-dimensional 1060-nm optical coherence tomography. Invest Ophthalmol Vis Sci 52(8):5311-5316

31. Esmaeelpour M, Brunner S, Shahrezaei S, Nemetz S, Povazay B, Kajic V et al (2012) Choroidal thinning in diabetes type 1 detected by 3-dimensional $1060 \mathrm{~nm}$ optical coherence tomography. Invest Ophthalmol Vis Sci 53(11):6803-6809

32. Lee HK, Lim JW, Shin MC (2013) Comparison of choroidal thickness in patients with diabetes by spectral-domain optical coherence tomography. Korean J Ophthalmol 27(6):433-439

33. Vujosevic S, Martini F, Cavarzeran F, Pilotto E, Midena E (2012) Macular and peripapillary choroidal thickness in diabetic patients. Retina 32(9):1781-1790

34. Querques G, Lattanzio R, Querques L, Del Turco C, Forte R, Pierro L et al (2012) Enhanced depth imaging optical coherence tomography in type 2 diabetes. Invest Ophthalmol Vis Sci 53(10):6017-6024

35. Dimitrova G, Kato S, Tamaki Y, Yamashita H, Nagahara M, Sakurai M et al (1994) Macular and peripapillary choroidal thickness in diabetic patients. Am J Ophthalmol 146(11):238-247

36. Kim JT, Lee DH, Joe SG, Kim JG, Yoon YH (2013) Changes in choroidal thickness in relation to the severity of retinopathy and macular edema in type 2 diabetic patients. Investig Ophthalmol Vis Sci 54(5):3378-3384

37. Kase S, Endo H, Yokoi M, Kotani M, Katsuta S, Takahashi M et al (2015) Choroidal thickness in diabetic retinopathy in relation to long-term systemic treatments for diabetes mellitus. Eur J Ophthalmol. 29:0

38. Ferreira J, Vicente A, Proença R, Dias-Santos A, Santos B, Cunha JP et al (2015) Choroidal thickness in diabetic patients without diabetic retinopathy. Acta Ophthalmol. 93(S225)

39. Ferrara D, Waheed NK, Duker JS (2015) Investigation the choriocapillaris and choroidal vasculature with new optical coherence tomography technologies. Prog Retin Eye Res

40. Xu J, Xu L, Du KF, Shao L, Chen CX, Zhou JQ et al (2013) Subfoveal choroidal thickness in diabetes and diabetic retinopathy. Ophthalmology 120(10):2023-2028

41. Gerendas BS, Waldstein SM, Simader C, Deak G, Hajnajeeb B, Zhang L et al (2014) Three-dimensional automated choroidal volume assessment on standard spectral-domain optical coherence 
tomography and correlation with the level of diabetic macular edema. Am J Ophthalmol 158(5):1039-48.e1

42. Zhang Z, Meng X, Wu Z, Zou W, Zhang J, Zhu D et al (2015) Changes in choroidal thickness after panretinal photocoagulation for diabetic retinopathy: a 12-week longitudinal study. Invest Ophthalmol Vis Sci 56(4):2631-2638

43. Cho GE, Cho HY, Kim YT (2013) Change in subfoveal choroidal thickness after argon laser panretinal photocoagulation. Int $\mathrm{J}$ Ophthalmol 6(4):505-509

44. Laíns I, Figueira J, Santos AR, Baltar A, Costa M, Nunes S et al (2014) Choroidal thickness in diabetic retinopathy: the influence of antiangiogenic therapy. Retina 34(6):1199-1207

45. Yiu G, Manjunath V, Chiu SJ, Farsiu S, Mahmoud TH (2014) Effect of anti-vascular endothelial growth factor therapy on choroidal thickness in diabetic macular edema. Am J Ophthalmol 158(4):745-51.e2

46. Lee SH, Kim J, Chung H, Kim HC (2014) Changes of choroidal thickness after treatment for diabetic retinopathy. Curr Eye Res 39(7):736-744

47. Gupta P, Cheng C-Y, Cheung CMG, Htoon HM, Zheng Y, Lamoureux EL et al (2015) Relationship of ocular and systemic factors to the visibility of choroidal-scleral interface using spectral domain optical coherence tomography. Acta Ophthalmol 1-8

48. Jo Y, Ikuno Y, Iwamoto R, Okita K, Nishida K (2014) Choroidal thickness changes after diabetes type 2 and blood pressure control in a hospitalized situation. Retina 34(6):1190-1198
49. Bourke K, Patel MR, Prisant LM, Marcus DM (2004) Hypertensive choroidopathy. J Clin Hypertens (Greenwich) 6(8):471-472

50. McMahon TT, Maino JH (1982) Hypertensive choroidopathy. J Am Optom Assoc 53(9):713-717

51. Akay F, Gundogan FC, Yolcu U, Toyran S, Uzun S (2015) Choroidal thickness in systemic arterial hypertension. Eur J Ophthalmol 8:0

52. Wong IY, Wong RL, Zhao P, Lai WW (2013) Choroidal thickness in relation to hypercholesterolemia on enhanced depth imaging optical coherence tomography. Retina 33(2):423-428

53. Gupta P, Jing T, Marziliano P, Baskaran M, Cheung GCM, Lamoureux EL et al. (2015) Peripapillary choroidal thickness assessed using automated choroidal segmentation software in an Asian population. Br J Ophthalmol. 1-7

54. Lee JY, Lee DH, Lee JY, Yoon YH (2013) Correlation between subfoveal choroidal thickness and the severity or progression of nonexudative age-related macular degeneration. Invest Ophthalmol Vis Sci 54(12):7812-7818

55. Kang HM, Kwon HJ, Yi JH, Lee CS, Lee SC (2014) Subfoveal choroidal thickness as a potential predictor of visual outcome and treatment response after intravitreal ranibizumab injections for typical exudative age-related macular degeneration. Am J Ophthalmol 157(5):1013-1021 